\title{
A ESCRITA EPISTOLAR, A LITERATURA E OS JORNAIS DO SÉCULO XIX: UMA HISTÓRIA
}

\section{THE EPISTOLARY WRITING, LITERATURE AND NEWSPAPERS OF THE NINETEENTH CENTURY: A BRIEF HISTORY}

\author{
Socorro de Fátima Pacífico Barbosa*
}

RESUMO: Desde fins do século XIX quando a literatura passou a ser lida a partir de critérios evolucionistas e, depois no século XX, estéticos, a história da literatura passou a se apropriar anacronicamente dos objetos escritos no passado, adaptando-os para os valores da sua contemporaneidade. Esta prática determinou o apagamento histórico de alguns gêneros como a carta e suas infinitas possibilidades de escrita, objeto literário no contexto do Oitocentos. Este artigo visa trazer esta prática para o contexto de sua produção, principalmente, no que tange à sua produção nos jornais e periódicos da época, inserindo-a na tradição da carta apologética.

PALAVRAS-CHAVE: escrita epistolar, gêneros literários, jornais e periódicos do século XIX.

ABSTRACT: Since the late nineteenth century when literature began to be read from evolutionary criteria and then in the twentieth century, from aesthetics criteria, the history of literature began to anachronistically take ownership of objects written in the past, adapting them to the values of their contemporary. This practice has determined the historical erasure of some genres such as the letter and its infinite possibilities for writing a literary object in the context of production, mainly in relation to its production in the newspapers and the nineteenth century. This article aims to bring this practice to the context of its production, mainly in relation to its production in the newspapers and periodicals of the time, inserting it in the tradition of the apologetic letter.

KEYWORDS: epistolary writing, literary genres, newspapers and periodicals of the nineteenth century.

\footnotetext{
* Universidade Federal da Paraíba (UFPB), João Pessoa/PB. Professora Associada II do Departamento de Letras Clássicas e Vernáculas (DLCV). Doutora em Literatura Brasileira pela Universidade de São Paulo (USP). Email: socorrofpb@yahoo.com.br.
} 



\section{A ESCRITA EPISTOLAR, A LITERATURA E OS JORNAIS DO SÉCULO XIX: UMA HISTÓRIA}

Quando iniciei a pesquisa ${ }^{1}$ sobre a escrita epistolar nos jornais e nos periódicos brasileiros, julguei que a tradição epistolar encontrada desde os primórdios neste suporte estaria, primeiramente, relacionada aos princípios da ars dictaminis e das regras rígidas dos códigos epistolares. Estas eram disseminadas no Brasil via o Secretário, de Candido Lusitano ou Francisco José Freire, apontado como o segundo livro mais presente em inventários e testamentos do Brasil Colonial (ARAUJO, 1999). ${ }^{2}$ Também considerei com Carvalho (2010) a influência do ensino da retórica, presente no Brasil desde o século XVI, com o ensino dos jesuítas, e depois a sua retomada pela reforma pombalina, com a implantação das aulas régias. Estas classes

1 Pesquisa desenvolvida com o apoio do CNPq. Todos os jornais e livros que não estão disponíveis on line, nem dispõem de edições impressas foram pesquisados na Fundação Biblioteca Nacional, no Setor de Obras Raras daquela instituição, conforme esboçado no projeto de pesquisa.

2 Contudo, vários são os indícios de circulação desses compêndios. Muitos podem ser encontrados em anúncios das livrarias e das boticas, como a que se verifica no jornal paraibano A Regeneração, de 1862, em que, em um único reclame, encontram-se dois títulos desses compêndios. Um deles, o Novíssimo Secretário Português, ou método de escrever cartas, Francisco José Freire de Carvalho, o Candido Lusitano, obra de 1745, que teve sucessivas reedições a atestar os seus usos e atualizações; o outro era o Manual epistolar para ensinar a fazer cartas (BARBOSA, 2007). Alguns estão nos catálogos das livrarias, outros ainda permanecem nos arquivos da Biblioteca Nacional e do Real Gabinete de Leitura. 
foram criadas na colônia e "apesar do pequeno número" garantiam "que no início do século XIX qualquer pessoa com alguma educação acima da alfabetização elementar, em Portugal ou no Brasil, teria passado por elas e, portanto, teria alguma formação em retórica" (CARVALHO, 2010, p.133). As aulas de retórica eram ajudadas pela publicação de manuais destinados ao ensino da disciplina no Brasil e em Portugal, como o de Francisco Freire de Carvalho, Lições elementares de Eloquência Nacional. ${ }^{3}$ Esta publicação, juntamente com a do Padre Miguel do Sacramento Lopes Gama, Lições de eloquência nacional, professor da Faculdade de Direito de Olinda, impressa por Paula Brito em 1846, teriam moldado o modo de escrever cartas em jornal e em periódicos do século XIX brasileiro. Com a fundação do Colégio Pedro II e a inclusão da cadeira de retórica, ocupada por importantes homens de letras do período, através de concurso público, o mérito destas publicações também passou a ser de outros brasileiros, que deram à luz uma série de compêndios com esta destinação (SOUSA, 1999).

Carvalho (2010) considera a retórica a chave para a leitura da história intelectual do Brasil e também acredita que sua insistente presença deriva do seu ensino ou do seu conhecimento por meio de manuais populares. Disto resultaria, principalmente, o aspecto ornamental, oco, das obras dos escritores brasileiros, nas quais predomina a palavra sonora, a citação de autores, tradição herdada da educação escolástica dos jesuítas, que teria perdurado por séculos no Brasil. Nem mesmo a reforma de Pombal retirou o prestígio da retórica, tampouco a eliminou como disciplina, sendo apenas reformada em suas bases.

Exemplo do prestígio da retórica seria o Verdadeiro método de estudar, de Luis António Verney (1746), ${ }^{4}$ que, a despeito de criticar todo o excesso de ornamento e a infinidade de citações de autores e obras como sinônimo de obscuridade, quando convidado a promover a reforma dos estudos, louvou a disciplina e buscou em seu método ensinar aos portugueses a "verdadeira” retórica, cuja função era persuadir, instruir e deleitar. Mas, retomando o ponto de vista de Carvalho, depois de apresentar seus argumentos, ele afir-

3 Lições elementares de Eloquência Nacional, publicado no Rio de Janeiro, pela Laemmert, em 1834, com a segunda edição pela Tip. Rollandiana, em 1840; Lições de eloquência nacional, impressa pela editora de Paula Brito, em 1846.

4 Este livro também foi escrito em forma de cartas, utilizando-se do mecanismo retórico da dissimulation, uma vez que seu autor utiliza o pseudônimo de Barbadinho, da Congregação de Itália. 
ma que "se os indícios da existência no Brasil, ou em qualquer outro país, de uma cultura marcada pela retórica são verdadeiros, então o protocolo de leitura fornecido pela argumentação deveria ter utilidade na decifração dos textos produzidos dentro dessa cultura" (2010, p. 139). A partir desta premissa, o historiador acredita que "alguns problemas encontrados na prática da história intelectual do Brasil poderiam ter sua solução facilitada com o auxílio das sugestões tiradas do modo retórico de argumentar" (Ibidem).

Em outras palavras, tal qual à história da literatura não interessou, durante muito tempo, analisar em que medida essa relação de dependência entre o suporte, a linguagem e os leitores interferia na produção final deste produto a que chamam, de forma genérica, de literatura do século XIX, no campo da história da cultura também se pode observar, conforme afirma José Murillo de Carvalho, que àqueles historiadores não importou indagar sobre "os contrastes no campo da linguagem, dos estilos de pensar, dos modos de discurso, das práticas retóricas” (2010, p. 137).

A partir desta perspectiva, defendo que, aos estudos literários relativos à primeira metade do século XIX, principalmente à maneira da história das mentalidades, seja aplicada a retórica como chave de interpretação. A data de 1836, relativa "à inauguração do romantismo no Brasil", não pode abolir o processo histórico de circulação dos objetos culturais, nem quando estudamos as relações entre a imprensa e sua interferência tanto na elaboração de obras quanto na predominância de determinado gênero, além da consagração de um autor e da criação do cânone. Ao adotar este procedimento, esta pesquisa permitiu ir além dos meros registros ou da valorização a priori de determinados jornais, a partir da perspectiva da participação deste ou daquele jornalista, ou de ser desta ou daquela época. Em outras palavras, retirou-se da imprensa brasileira o lugar de testemunho "inconsistente" e "duvidoso" dos fatos e da história para instituí-la como objeto de análise do presente daquela enunciação, como lugar de práticas discursivas, de ditos e de "não ditos", explicitados nos recortes e nas escolhas dos historiadores (CERTEAU, 2006, p. 67). Dizendo de outro modo, a partir da perspectiva da história cultural, a multiplicidade e a heterogeneidade de vozes que construíram o suporte jornal ampliam-se, se não nos deixarmos envolver pela catalogação, fixação e hierarquia de certas construções historiográficas, entre elas a que estabeleceu uma hierarquia entre os gêneros. Segundo Chartier (2007, p. 17), esta perspectiva garante a possibilidade de identificar de forma mais "verossímil" o modo como aquele passado, ou "realidade social [foi] construída, pensada, dada a ler". 
À escrita epistolar nos jornais e periódicos brasileiros do século XIX, pode-se aplicar o que Carvalho (2010) elenca como "problemas". Primeiramente, "o estilo do debate político", que se caracteriza pela violência da linguagem, o ataque pessoal, o argumento ad personam. ${ }^{5} \mathrm{~A}$ justificativa retórica pode colocar por terra o que os historiadores consideravam falta de maturidade dos jornalistas brasileiros, pouco acostumados com a utilização dos argumentos e mais com ataques pessoais. Se, por um lado, "há na explicação uma visão talvez excessivamente negativa do fenômeno da violência verbal", por outro, este fenômeno pode ser "visto como imaturidade, falta de educação, incivilidade. Se olhado pelo prisma da retórica, tal imagem negativa pode ser matizada"(CARVALHO, 2010, p. 140), pois, segundo o autor, no mundo da retórica não se separam a autoridade do orador e a do argumento. Embora verdadeira do ponto de vista da retórica, esta premissa se mostra inconsistente na prática da escrita epistolar dos periódicos em dois pontos: primeiro, quando indagamos como redatores virulentos e violentos podem querer ser confundidos com a sua palavra, pouco adequada e indecorosa, que revelaria a falta de virtude, de honestidade e de competência argumentativa, todas as qualidades exigidas daquele que escreve ou fala; segundo, mesmo quando consideramos, como quer Carvalho (Ibidem), que os jornalistas estavam debatendo a matéria política que denunciava sua própria ação, bem como a do adversário, devese considerar, conforme veremos, que, do ponto de vista da construção discursiva da linguagem, aqueles jornais e periódicos do século XIX apresentavam uma multiplicidade de vozes em sua composição. Embora ao redator cumprisse o papel de selecionar, de extrair, de adaptar e de, muitas vezes, traduzir todas as matérias, também era dele a possibilidade de publicação das vozes de crítica e de oposição (BARBOSA, 2010). Os periódicos do século XIX eram por excelência lugar onde se encontravam várias vozes, vários auditórios, várias comunidade de leitores, ampliando, em muito, o repertório de interpretação.

Um exemplo desse diálogo implícito que se verifica nesses suportes pode ser observado na seguinte "Resposta à Carta, publicada no Espelho", dirigida ao Sr. André Raposo, escrita por Hum Constitucional de Facto, e de Direito. ${ }^{6}$

\footnotetext{
5 Nesta argumentação, muito presente nos periódicos brasileiros do século XIX, o orador procura desacreditar o oponente de um ponto de vista pessoal, desacreditando, com isso, sua iniciativa argumentativa, como destituída de autoridade (LAUSBERG, 1967).

6 Optei por manter a grafia original da época tanto dos livros consultados quanto dos
} 
Apparecen em fim o novo meteoro fulminante na orbita do Espelho!!! A falta de Folhas Francezas, ou a sua lamentada esterilidade tem obrigado o seu Redactor a por em contribuição os infectos chilradores, e agora os Andrés. Seria porém melhor, que elle, já que tão desgraçado na escolha de partos alheios, se deixasse transcrever frioleiras, continuando a suprir a falta de proprio cabedal com as compilações do Diario do Governo, e remendiando a tortura, em que o poem as Gazetas Francezas com duplicadas Listas de preços correntes, de carregamento, ou Tripulação das Embarcações que entraõ, e sahem. A Lição que lhe deu o Alfaiate devia torna-lo mais cauteloso: mas diz o Ditado "quem torto nasce nunca se endireita" e em ventas estragada podem muito fumaças de Lisonja. Fallava-se de $=$ Zoilos $=$ que atacarão o $=$ Chefe de Obra $=$ da memoranda Xilradella; e o novo Erostrato de correspondencias Epistolares não pôde suffocar a vangloria de fazer publico o sediço louvor $=$ em fraze estrangeiral $=$ Teve juiso ( contra o costume) Snr. Andre; porque se lhe não dá com este mel pela boca do asno, duvido que a tal diatribe fosse impressa sem custar-lhe dinheiro para os lugares em que tem uso o papel pardo (Reverbero Constitucional Fluminense, 729 jan.1822).

Estre trecho de carta ao mesmo tempo em que demonstra os modos de escrever, também revela o diálogo implícito que se trava, neste caso, entre dois jornais, dois leitores e dois escritores de cartas. Contudo, o mais característico desta escrita é observado por Conway (2006, p. 77), na Gaceta de Caracas, mas pode ser extensivo aos periódicos luso-brasileiros. Ou seja, "apesar de o periódico esgrimir a palavra como instrumento de controle social, também a utiliza para deslegitimar sua própria autoridade escrituária; a palavra se torna arma contra a palavra do outro". Assim, ao desautorizar a escrita de André, em O Espelho, "Um Constitucional de Facto e de Direito" traz para o Reverbero a palavra deste outro com a qual esgrima.

periódicos, inclusive seus inúmeros erros tipográficos.

7 O jornal Reverbero Constitucional Fluminense merece um estudo a parte, uma vez que é basicamente composto por correspondência em forma de carta ou não. Talvez esta seja uma das prerrogativas de ter sido o primeiro jornal, segundo Lustosa (2003, p. 23) "a usufruir do fim da censura e a defender por escrito as ideias preconizadas na Revolução Francesa”.

8 Tradução livre do espanhol.

9 Periódico redigido pelo Coronel Manuel Ferreira de Araújo Guimarães, fundador da revista O Patriota, de 1813-1814, e ex-redator, entre 1813 e 1821, da Gazeta do Rio de Janeiro (VIANNA, 1945, p. 510). 
Outro aspecto mencionado neste trecho e bastante recorrente nos periódicos era traduzir, por meio desses escritos "metalinguísticos", a elaboração e o uso dos elementos discursivos que caracterizavam a escrita jornalística. Entre estas práticas de escrita estava a de, às vezes, extrair trechos inteiros, outras, de fazer paráfrases de jornais que extrapolavam em muito o universo luso-brasileiro. O que Hum Constitucional critica é o mau uso desta prática, revelada pela publicação de "Listas de preços correntes, de carregamento, ou Tripulação das Embarcações que entraõ, e sahem”. Estas práticas dizem respeito a um processo de longa duração, que pode ser identificado em periódicos do início ao fim do século (BARBOSA, 2007). Tome-se como exemplo jornais de épocas distintas - Colônia, Primeiro e Segundo Reinados - de províncias distintas - Bahia, da Corte ou de Pernambuco. Mas até mesmo entre os jornais brasileiros e portugueses, ou brasileiros e ingleses, porém como prática de escrita jornalística da época. Não se pode também esquecer-se da circulação física e material que tinham estes periódicos, que tanto transitavam pelo Brasil quanto eram exportados para outros países. A circulação dos periódicos no século XIX pode ser comparada, guardadas as devidas proporções, ao que víamos no século passado com os jornais e atualmente se revela em sites, o que amplia em muito a relação do Brasil para além do mundo Ibérico. Por isso, o estudo da imprensa brasileira do século XIX obrigatoriamente necessita ser inserido em contexto que inclua os jornais europeus e latino-americanos. A leitura diacrônica dos periódicos brasileiros feita por esta pesquisa vai revelando esta grande teia de comunicação elaborada por correspondentes, extratos, assinatura de jornais por bibliotecas e gabinetes de leitura.

No Brasil, assim como na França do século XVIII, "as pessoas educadas começaram a ler 'extensivamente'. Liam grande quantidade de matéria impressa, especialmente romances e jornais, os gêneros favoritos nos clubes de leitura que proliferavam em toda parte, nos centros urbanos" (DARNTON, 2001, p. 319). Como observamos em vários periódicos, a assinatura de jornais do país e do exterior era uma prática quase obrigatória dos gabinetes de leitura e das bibliotecas públicas que se fundavam no Brasil.

Sobre a "importação" de matérias de outros jornais, o exemplo inicial é o do primeiro número do jornal Idade d'Ouro do Brasil, ${ }^{10}$ de 14 de maio de

${ }^{10}$ O jornal Idade de Ouro do Brasil foi o primeiro jornal publicado em Salvador. Existiu de 1811 a 1818. Como os periódicos da época, seu formato era in $4^{\circ}$, circulava às terças 
1811. Observe-se que o jornal não se apresenta, não diz a que veio, mas abre seu exemplar inaugural com a palavra GRAMBRENTANHA após os dados e a epígrafe, seguindo com notícias daquela região. O jornal informa: Londres, 10 de janeiro de 1811.

Quarta feira do corrente teve lugar a Ceremonia da installação dp Princepe de Galles em Regente da Gram-Bretanha por virtude de hum acto do Parlamento, que em consequência do estado de molestias do Rei seu Pai Declarou que aquelle Principe pertencia a Regencia dos Reinos Unidos em Nome, e com o consentimento de SUA MAGESTADE BRITANICA.

Esta maneira de inaugurar um jornal sugere haver entre os seus leitores uma partilha sobre o modo como as "notícias" são apresentadas e o consenso sobre "extraí-las" de vários jornais brasileiros e estrangeiros. Outro exemplo escolhido de forma aleatória, do mesmo jornal, publicado no $\mathrm{n}^{\mathrm{o}}$ 88 , de $1^{\circ}$ de novembro de 1814 , demonstra a sem cerimônia com que o redator informa aos seus leitores que extrairá - o extrato é um gênero presente nos periódicos da época - "Dos Investigadores portugueses na Inglaterra alguns documentos para fazer entrar os Leitores na inteligência destes delicados negócios”. No no 103 da Idade d'Ouro, de 26 de dezembro de 1815 , observa-se que "extrair" matérias de outros jornais é, sobretudo, uma qualidade para a escrita da época:

\section{BAHIA.}

A Typographia desta Cidade está em grande ponto de perfeiçaõ, naõ só pela quantidade, e variedade de typos, que lhe tem vindo da Inglaterra como pela pericia e exactidaõ dos Compositores. O seu Proprietario abrio huma correspondencia para Londres, e Paris a fim de ter sempre os melhores Periodicos da

e sextas-feiras. Tinha como epígrafe a frase de Sá e Miranda: "Falai em tudo verdades, a quem em tudo as deveis". O jornal era impresso na Tipografia de Manuel Antonio da Silva Serva. Cf: VIANNA, Helio. Contribuição à história da imprensa brasileira. 1812 -1869. Rio de Janeiro: Imprensa Nacional, 1945. A consulta aos periódicos Idade de Ouro do Brasil e Gazeta do Rio de Janeiro foi feita na página dos Periódicos Digitalizados da Fundação Biblioteca Nacional. Disponíveis, respectivamente, em: <http://objdigital.bn.br/acervo_ digital/div_periodicos/idadedouro/idadedouro.htm $>$; $<$ http://objdigital.bn.br/acervo_ digital/div_periodicos/gazeta_rj/gazeta.htm>. 
Europa para a redacção da Gazeta, a qual se fará mais interessante á medida, que crescerem os materiaes, donde se possa extrahir alguma curiosidade, ou alguma relfexaõ de literatura, e política. Todas as Gazetas do Mundo saõ sempre estereis quando naõ ha guerras, ou grandes fermentações politicas; nesse caso deve o Redactor enfeitar a Gazeta á maneira de Jornal sob pena de naõ ser lido, á excepçaõ de algum caso, que toca o interesse Publico, o que raras vezes acontece (Grifos do autor).

Outro exemplo é o retirado de um jornal da Corte, a Gazeta do Rio de Janeiro, do mesmo período, ou seja, o no 37, de 11 de maio de 1811, no qual o redator adverte os leitores: "Os nossos Leitores não deixarão de se interessar, vendo a carta seguinte que extratamos [sic] do Courier de Londres sobre a saúde d'El-Rei da Grã-Bretanha, a qual data de Windsor em 27 de Janeiro". ${ }^{11}$ Da mesma forma, o primeiro número do primeiro jornal brasileiro, Gazeta do Rio de Janeiro, de 10 de setembro de 1808, traz o Extrato de uma carta de Londres, do dia 16 de junho, escrita a bordo do Startira. A carta dá notícias sobre o levante dos moradores da Espanha ao cerco dos soldados franceses.

Evidentemente que vamos encontrar esta mesma prática de escrita em periódicos portugueses, mas optamos por demonstrar o caráter generalizado deste modo de escrever com um periódico de Nova York, o The Nation, weekly journal, devoted to Politics, literatures, Sciencias and Arts, ${ }^{12}$ de 20 de fevereiro de 1868, no qual se verifica a mesma teia entre os periódicos, o mesmo modo de comunicar, de citar, de se inteirar dos assuntos, identificado aqui no Brasil:

A correspondent at Marquette, Michigan, sends us some proofs that Messers. Clarke \& Bowron, publishers in Chicago, are practicing on the reading public, at our expense, a deception like that one of which the Boston Nation was the other day proved guilty. They send to the Chicago Evening Journal what purports to be an extract form a notice in this journal of two books by a Dr. Thomas Clarke".

${ }^{11}$ Definitivamente, o critério de "atualidade", ou de notícia quente, não era algo presente nestes periódicos. É muito comum a presença de cartas, extratos, memórias, relação de viagens etc., nos quais observamos um largo arco temporal a separar o evento da sua publicação na folha.

${ }^{12}$ The Nation, weekly journal, devoted to Politics, literatures, Sciencias and Arts. vol. 5 and 6. Disponível em: <http://books.google.com.br/books>. Acesso em: 2 fev. 2011. 
Até mesmo os anúncios do surgimento de outros jornais, tão caros aos periódicos brasileiros e sobejamente conhecidos, também frequentam as páginas da imprensa americana, como este, do mesmo jornal, de 6 de fevereiro de 1868, "From the London Pall Mall Gazette. These essays are a reprint from New York Nation - a newspaper which has done much to show that American journalism may attain a far higher level than that to which we have hitherto been accustomed".

Em seu primeiro número, o redator de Idade d'Ouro implora, em solicitação escrita na última página, a colaboração do seu leitor, outra prática que conforme veremos também precisa ser considerada quando se analisa a produção epistolar nos periódicos do Oitocentos. ${ }^{13}$ Um aviso na última página do Compilador Mineiro de 22 de outubro de 1823 demonstra a participação efetiva dos leitores neste processo de elaboração heterogêneo do jornal: "O Srs que nos tem mandado Impressos para delles extractarmos alguns artigos para o nosso Periódico, logo que forem publicados, podem mandar pelos Impressos para não truncarem suas obras, o que o Redactor não faz por suas occupações e muito lhes agradece o favor, e, espera sua continuação". ${ }^{14}$ Este exemplo revela como os epítetos de liberal, conservador, monarquista ou republicano, ou tantos outros com que são classificados estes periódicos desde o século passado, não são suficientes para uma apropriação mais coerente destes objetos de cultura, a partir de "legibilidades verossímeis", que visam "ajustar a interpretação dos textos à sua forma histórica contingente" (PÉCORA, 2001, p. 11). Estas leituras, embora apropriadas do ponto de vista do seu estudo político, deixam de lado o caráter dialógico por excelência que os periódicos possuíam, considerando-se a noção de diálogo segundo

\footnotetext{
${ }^{13}$ Segue o Aviso do redator: "O Redator implora a todas as Pessoas, especialmente aos Senhores Comerciantes, cujas relações com outras Praças assim Nacionais como Estrangeiras, são mais amplas, a bondade de lhe comunicar todos os artigos que nas suas Cartas acharem dignos de merecer a atenção do Público, ou sejam tendentes ao melhoramento das Artes, Ciências, ou úteis ao Comércio, e que possam servir de sintoma do estado atual dos Negócios políticos de todo o Mundo. Os desejos do Redator, de que a nossa folha Idade douro do Brasil mereça conceito e aprovação geral, e os vivos esforços para que o seu contexto corresponda ao brilhante titulo, serão beldados [sic], se o mesmo Público não coadjuvar uns, e outros subministrando alguns elementos para a instrução geral".

${ }^{14}$ Compilador Mineiro. Considerado o primeiro periódico mineiro, era publicado em Ouro Pedro, nas Oficinas de Patricia de Barboza e C. Jornal disponível em: <http://objdigital. bn.br/acervo_digital/div_periodicos/compilador_mineiro/compilador_mineiro.htm>.
} 
a concepção de Bakhtin (2004), com seu caráter polifônico; dessa forma, se tomamos esses escritos como polifônicos, eles o são justamente pelo fato de possibilitar que estas vozes sejam ouvidas e incorporadas.

De fato, esses exemplos revelam que - apesar das divergências ou convergências políticas, a unir ou a separar a "linha editorial" dos seus redatores, mesmo se considerarmos o estatuto do anonimato e de um recurso retórico bastante presente na escrita jornalística do século XIX - aí está a dissimulation. Segundo Lausberg (1967), a dissimulation pode se manifestar sob os mais variados aspectos: através da alegoria, da perífrase, da ironia retórica, da simulação de ingenuidade, da personificação. Essa premissa ajuda a compreender uma prática de escrita característica da imprensa do século XIX, ${ }^{15}$ que é a utilização sistemática de pseudônimos ou de textos anônimos, pois, neste caso, é ao suporte jornal que se confere a credibilidade e a autoria daquilo que estava escrito e não, como se supõe de forma anacrônica, na perspectiva do autor como instância subjetiva e pessoal. Este artifício retórico no contexto da imprensa do século XIX prevê, inclusive, o disfarce do redator em leitor do jornal e a utilização destas estratégias demonstra a necessidade de se apropriar desses periódicos a partir da noção de representação. Mais do que máscaras sob as quais os escritores/leitores se escondem, os pseudônimos dos periódicos brasileiros traduzem com bastante propriedade a posição destes em relação ao presente histórico, aos acontecimentos políticos e sociais, bem como à linha do jornal e mereceria um estudo à parte, que não cabe nos limites deste trabalho.

Dizendo de outro modo, uma peça escrita de um jornal carioca, ou londrino, ou francês, poderia ser aproveitada em qualquer tempo ou sob qualquer circunstância por um jornal paraibano, pernambucano ou gaúcho, o que ampliava e indeterminava completamente este "auditório" imaginário para quem os autores escreviam, dando-lhes inclusive outros usos e apropriações. Definitivamente, os usos e apropriações dos impressos era algo marcado pelo imprevisto, pela falta de assunto e, consequentemente, pelo improviso. Ou, como afirma Carvalho, na perspectiva retórica "é fundamen-

\footnotetext{
${ }^{15}$ Schopenhauer (2006, p. 76) se posiciona contra "este escudo de toda patifaria literária", bastante comum à imprensa alemã e, segundo o que afirma, também usual na França. Para o filósofo, "na literatura, enquanto não existir essa proibição, todos os escritores dignos deveriam unir-se para proscrever o anonimato com o estigma de um desprezo público, incansável e diariamente expresso, demonstrando de todas as maneiras a noção de que escrever críticas anonimamente é uma indignidade e uma desonra”.
} 
tal levar em conta a audiência para que se fala", uma vez que "as audiências variam muito em índole, engenho, educação, conduta, costumes; variam segundo as nações, reinos e mesmo províncias. O tipo de audiência determina o estilo do orador e os argumentos" (2010, p. 135). Assim, ler, interpretar e traduzir qualquer escrita jornalística do século XIX, ou "explorar a possibilidade de usá-la como instrumento de trabalho na prática da história intelectual", como o quer José Murilo de Carvalho, implica retomar a materialidade retórica e histórica desses escritos. Dizendo com Pécora, pode-se aplicar à pesquisa histórica o mesmo que se verifica com relação aos estudos da história da literatura, o que significa

então, reconhecer que estes estudos não se aproximam, agora, de algo mais profundo ou preciso a propósito dos objetos tratados; não descobre um método melhor, no sentido de mais seguro ou necessário, segundo um critério universal ou racional neutro. Apenas podem, com sorte, responder mais eficazmente a uma situação presente da história, que já não parece acatar como crível que a linguagem seja representação de etapas sucessivas, historicamente mais completas e plenas, à imagem de um espírito que progressivamente se torna mais capaz de reconhecer a si mesmo (2001, p. 16).

A partir do exposto, passo à análise da escrita epistolar no corpo de jornais e de periódicos luso-brasileiros. Antes, porém, é preciso defender que, com relação a esta prática e seus produtos, pode-se acrescentar às hipóteses de Lima Sobrinho (1960), com relação ao conto, e às de Meyer (1996), no que se refere às crônicas e aos folhetins, que esse gênero foi também constitutivo das práticas de escrita responsáveis pela formação da literatura brasileira.

\section{A carta como objeto literário: das news/etters manuscritas às epístolas em jornais do século XIX}

A despeito dos vários estudos sobre a carta, ainda se sabe muito pouco sobre a sua existência como objeto de cultura escrita, ou como objeto "literário", principalmente pelo fato de a abordagem estética da literatura, desde o início do século XX, excluir a carta dos gêneros literários, deixando-a como objeto da história da literatura, da sociabilidade e da vida literária. ${ }^{16}$

\footnotetext{
${ }^{16}$ Os estudos sobre a escrita epistolar no Brasil já estão consolidados no campo da educação
} 
A opinião de Moisés, segundo a qual, "no século XX, a carta literária desapareceu, dando lugar à missiva real entre escritores” (1985, p. 193), parece ter sido aplicada ao gênero epistolar, em épocas anteriores, o que colaborou, inclusive para tirar o gênero do cânone literário, ficando a exceção aos escritos dos jesuítas, notadamente, as Cartas do Padre Vieira. ${ }^{17}$ Mesmo os estudos mais recentes tendem a não mencionar as características históricas deste gênero regrado, em seus mais variados aspectos, entre os quais a possibilidade de ser escrita em verso ou em prosa e de ser um objeto "literário". Este artigo, cujo objetivo último é restaurar a prática histórica do gênero epistolar nos periódicos brasileiros, busca também "demonstrar que aquilo que ela tem de convenção e artifício é exatamente o mesmo que tem de produto histórico" (PÉCORA, 2001, p. 16) e, como tal, deve ser apropriada.

Pesquisar a carta nos periódicos brasileiros não é tarefa das mais simples. Pode-se afirmar que de 1808 , data em que teve início a imprensa brasileira, ao fim do século XIX, a carta foi o gênero por excelência de escrita neste suporte, principalmente, para matérias de debate, contendas e batalhas literárias. O primeiro passo é retomar o conceito de "literatura" próprio ao seu tempo, compreendido aqui até a década de 60 do século XIX, e com ele trazer os objetos que eram considerados "literários" à época. Em 1856, o livro Elementos de litteratura, contendo a arte Poetica, a Mythologia, a Idiologia, a Grammatica, a Logica, e a Rhetorica, de Mello Moraes, assim se pronuncia sobre o "dominio da litteratura" e o que "compem o seu imperio". Segundo o autor, "a grammatica, a eloquencia, a poesia, a historia, a critica, e todos os conhecimentos humanos que não dependem de rigorosa demonstração" (1856, p. 1). Em 1862, o cônego Fernandes Pinheiro lança o seu Curso elementar de literatura nacional, o primeiro compêndio destina-

e da história (BASTOS et al. (org.); GOMES, 2004). A reabilitação dos estudos biográficos e as novas abordagens da história das mentalidades e da vida privada conferiram valorização dessa fonte, exigindo, assim, a sua recolha, organização e socialização para o desenvolvimento de pesquisas históricas. Aos historiadores interessam a correspondência de homens "comuns" e a dos "grandes" homens, principalmente aquela concernente "à escrita de si, uma forma de produção de memória que merece ser guardada e lembrada”(GOMES, 2004, p. 18). No âmbito da história da literatura, já se tornou tradição o uso da correspondência como fonte para o estudo das relações de sociabilidade entre escritores, dos estudos biográficos e da compreensão de momentos importantes dessa história, através da compilação e publicação de correspondência de autores célebres (GALVÃO; GOTLIB, 2000; AMED, 2006; Revista Teresa, 2008).

${ }^{17}$ Sobre o papel da carta nos quadros da história da literatura, consultar SILVA (2009). 
do ao ensino da literatura nacional e define-a "na sua mais ampla accepção", segundo frase de Lamartine, como

a expressão memorável do homem transimittida ao homem por meio da palavra escripta. Tomada porém em sentido restricto é a expressão dos conceitos, sentimentos e paixões do espirito humano feita por modo agradavel. É nesta última accepção que lhe cabe o epitheto de bellas letras, humanidades, ou boas letras, como tambem lhe chamavam os nossos classicos (PINHEIRO, 1862, p. 8).

Com efeito, como demonstra Abreu, na arqueologia que estabelece para o termo, a literatura não teve sempre, ao longo da história, o conceito que lhe é atualmente aplicado. Do século XVI, ${ }^{18}$ quando ainda não existia, passando pelo século XVIII, ${ }^{19}$ quando era chamado genericamente de Belas-Letras, ao

${ }^{18}$ Como afirma Márcia Abreu (2003, p. 11-12), "Em meados do século XVIII, Hamlet havia sido escrito há mais de 150 anos, os Lusíadas estavam publicados há quase 200 anos, $D$. Quixote fora impresso há 160 anos e, entretanto, ainda não havia literatura. Molière, Swift, De Foe, Corneille, Milton, Dante não escreviam literatura. Ou melhor, o que escreviam era literatura tanto quanto os textos de filósofos, historiadores, cientistas. Eram todos igualmente 'homens de letras', pois pertenceram a um tempo em que o termo literatura designava erudição" (Grifos do autor).

${ }^{19}$ A seguir, a definição de literatura proposta pela Enciclopédia: "LITERATURA (Ciências, Belas-Letras, Antiq.): termo geral que designa a erudição, o conhecimento das Belas-Letras e das matérias que com ela têm relação. Veja o verbete LETRAS, em que, fazendo seu elogio, se demonstra sua íntima união com as Ciências propriamente ditas”. Já o sentido de Letras, ao qual os autores remetem, é assim descrito: "LETRAS: essa palavra designa em geral as luzes advindas do estudo, e em particular aquela das Belas-Letras ou da literatura. Nesse último sentido, distinguem-se os homens de letras que cultivam somente uma erudição variada e plena de amenidades, daqueles que se apegam às ciências abstratas e àquelas de uma utilidade mais sensível. Mas não se pode adquiri-las em um grau eminente sem o conhecimento das letras. [...] Mas se as letras servem de chave para as ciências, as ciências, por seu lado, concorrem para o aperfeiçoamento das letras. [...] Para torná-las florescentes, é necessário que o espírito filosófico e, conseqüentemente, as ciências que o produzem encontrem-se no homem de letras, ou ao menos no corpo da nação. [...] A Gramática, a Eloqüência, a Poesia, a História, a Crítica, em uma palavra, todas as partes da Literatura seriam extremamente defeituosas se as ciências não as reformassem e não as aperfeiçoassem: elas são necessárias, sobretudo, às obras didáticas de retórica, de poética e de história. Para ter sucesso nesse gênero de obras é necessário ser filósofo assim como homem de letras (De Jaucourt)". DIDEROT, Denis; D’ALEMBERT, Jean le Rond (Org.). Encyclopédie, ou dictionnaire raisonné des sciences, des arts et des métiers, par une societé de gens de lettres. Paris, 1751-1772. Apud ABREU, Márcia. "Letras, Belas-Letras, Boas Letras", op. cit., p. 1415. (Grifos do autor). 
XXI, quando ainda não tem seus limites delimitados, o termo literatura designou práticas de escrita bastante variadas, cujos "critérios para a hierarquização de escritores e obras não estão claros e não foram centrados no exame dos textos" (2003). Para Abreu, "parte da eficácia do conceito de literatura está em que eleições e exclusões são feitas a partir de critérios pessoais, valores morais, políticos ou filiações estéticas não explicitadas" (ABREU, 2003, p. 64). Assim, observa-se um descompasso entre o que escritores no século XIX consideravam literatura e aquilo que os historiadores da literatura e os críticos do século XX passaram a nomear como tal.

De acordo com Pinheiro (1862), a carta ou epístola estava incluída entre os gêneros da literatura nacional, o que significava à época a portuguesa e a brasileira, assim como a historiografia, a oratória, a biografia e as viagens. No século XX, critérios anacrônicos e alheios ao passado começaram a determinar inclusive os objetos que deveriam ser incluídos sob o epíteto de literatura, processo responsável pelo apagamento de alguns desses gêneros, entre eles o epistolar e suas infinitas possibilidades de composição (BARBOSA, 2007).

Quando publicou seu livro no século XVIII, em pleno domínio da retórica, Freire (1823), no mais importante manual epistolar daquele tempo, compreendia a carta no âmbito dos objetos regrados, incluídos no campo das Belas-Letras. À carta eram aplicados os três gêneros presentes na oratória, a saber: os gêneros deliberativo, demonstrativo e judicial, pelos quais estão distribuídos os tipos mais correntes de cartas, principalmente as familiares, presentes na correspondência ordinária e, conforme se verá, presença constante nos jornais e nos periódicos. Entre as do gênero demonstrativo, estão as cartas de parabéns, de oferecimento, de agradecimento, de aviso, discursivas, de louvor; as cartas do gênro judicial são as de desculpa e de justificativa e a de queixa, fundamentais no âmbito da escrita política; por fim, o gênero deliberativo, no qual estão incluídas as cartas de pêsames, de recomendação, de boas festas, de consolação, de exortação e conselho (FREIRE, 1823). Mas o autor já previa em um tipo de carta, a carta mista, que merece uma advertência:

Muitas vezes succede escrever em huma mesma Carta diversas cousas; porque muitas vezes ha occasiaõ de pedir, agradecer, recommendar, etc. Naõ se póde dúvidar que similhantes Cartas saõ mixtas; porque aquelle, que as escreve, propõe em si diversos fins. Demos a estas o ultimo lugar, e com ellas constituimos 
quasi hum quarto genero; porque nos pareceo que naõ se comprehendiaõ bem nos outros. Naõ he necessario apontarmos regras para similhantes Cartas; porque bem sabe o Secretario que se deve servir dos preceitos particulares daquellas especies de Cartas, que nella se comprehenderaõ: como v. g. se ao mesmo tempo louvasse, e exhortação, etc (1823, p. 258, grifos do autor).

Parafraseando Freire de Carvalho (1856, p. 290), a carta, à primeira vista, pode "abranger um campo mui vasto; por não haver um só assumpto, sôbre o qual, quem quizer, não possa publicar seus pensamentos em fórma de Cartas". Contudo, adverte serem os limites da carta mais estreitos quando nela "predomina franqueza e familiaridade". Situada entre "as obras sérias e as de simples recreio", as cartas, mesmo as pessoais ou as familiares, como eram designadas no tempo, podem, desde que sigam as regras, servir de entretenimento. Contudo, como chama a atenção o autor, "a primeira condição ou regra, que a Arte da Oratoria impõe ao escriptor de Cartas, é que use de um estilo simples e natural; sendo que a demonstração de trabalho convém tão pouco a um Carta, como uma conversação". Estas observações vão ao encontro dos novos padrões de escrita epistolar que começavam a se delienar nos jornais e periódicos luso-brasileiros, interferindo diretamente na produção de manuais epistolares, entre os quais o famoso Secretário Português, ${ }^{20}$ de Candido Lusitano. Contudo, as regras da retórica, entre elas a da escrita epistolar como atividade regrada e artificial, que prevê um auditório, não está totalmente fora de propósito e permanece, com mudanças próprias aos gêneros, nos periódicos. Pois, como chama a atenção Francisco Freire de Carvalho,

\$Seria sem duvida uma puerilidade o julgar, que um escriptor manifesta em suas Cartas todo o fundo do seu coração; devendo pelo contrario presumir-se, que na

\footnotetext{
${ }^{20}$ Refiro-me especificamente ao Código Epistolar (1846), de José Ignacio Roquette, denominado de Novo secretário Português apenas a partir da segunda edição (1854), conforme prólogo publicado na terceira, no qual se observa a relação mais direta com o "velho" secretário de Candido Lusitano. Assim, ao mesmo tempo em que adere a este gênero antigo, a dos secretários, o autor agrega ao seu livro o epíteto Novo, para diferenciálo dos modelos pouco modernos. O exemplar que utilizamos corresponde à terceira edição de 1860. No Prólogo já referido, Roquette afirma as semelhanças e diferenças com o livro de Candido Lusitano: "[...] pelo que demos novo título a um livro em que se fizeram tão importantes modificações, e chamamos-lhes: Novo Secretário Português, por já existir um antigo, e porque este título justamente lhe pertence" (ROQUETTE, 1860, p. V).
} 
comunicação, ainda a mais intima, ha sempre algum disfarce, ou pelo menos, algua reserva: Todavia como Cartas, que as pessoas amigas escrevem umas às outras, são o que mais se aproxima á conversação familiar, é de esperar que nellas um caracter se dará a conhecer mais ás claras, do que nas obras escriptas para o publico: e é bem certo, que ninguem ha, que não deseje ver um escriptor em situação tal, que lhe permitta o pôr-se á sua vontade, e na qual deixe ressumbrar sequer alguas vezes os sentimentos, de que o seu coração está cheio (1856, p. 291).

Esta talvez seja outra explicação plausível para a carta ser o gênero por excelência das batalhas políticas e literárias travadas nos periódicos luso-brasileiros e motivar tanta curiosidade por parte dos leitores.

No século XVIII, era bastante recorrente a epístola em versos. No Brasil, o exemplo mais célebre é o das Cartas Chilenas, epístolas satíricas, atribuídas a Tomás Antonio Gonzaga, cuja linguagem traz todos os mecanismos empregados pela linguagem jornalística. Segundo Moraes, a epístola em verso deve seguir as mesmas regras do estilo epistolar e os versos exigem apenas "que tenha um gráo de força e de elegancia: em uma palavra, um gráo de cuidado acima do que lhe teria prestado se a escrevesse em prosa". Tal qual a epístola em prosa, a matéria da epístola em versos "é de uma extenção illimitada", uma vez que pode-se escrevê-la para "louvar, censurar, recontar, philosophar, dissertar e ensinar"21 (1856, p. 103). No que concerne aos tons de estilo, pode-se tomar que:

Todos os que existem convêm-lhe; porque seu estylo abaixa-se ou eleva-se, conforme a materia ou o estado da pessoa que escreve ou a quem se escreve. Ainda mais: a mesma epistola admitte todas as especies de tons, ou pelo menos todos aquelles que tendem á materia. A epistola em verso começa-se e termina-se sem atavios; e o titulo que tem é como um aviso ao leitor, de nao julgar a obra senão como se julga uma carta (1856, p.104).

A presença da epístola em verso pode ser identificada nos periódicos brasileiros até a década de 50 do século XIX, como se pode observar no exemplo a seguir, retirado de A Marmota, de 18 de maio de 1852. A carta

${ }^{21}$ Observe-se a mudança no vocabulário, que já não utiliza a nomenclatura tradicional em relação aos três gêneros retóricos identificados por Lusitano (1823, p. 30), a saber: gênero deliberativo; gênero demonstrativo; gênero judicial. 
trata de vários assuntos da Corte relativos ao mundo político e ao artístico. É bem longa e ocupa as duas colunas da primeira página e uma e meia da página dois.

Com pessoa já bem conhecida nesta corte abre hoje A Marmota uma nova correspondência, sob o título de "Carta a Jonio".

Amigo Jonio. - Saúde

E venturas te desejo:

Já de ti tenho saudades,

Pois há muito te não vejo.

Mas isto em nada destoi

A nossa antiga amizade,

Mantida no espaço de anos

Com lisura, e com verdade.

$$
[\ldots]
$$

Anda toda esta cidade

N'uma inteira confusão!

Joga de cima o governo,

E debaixo a oposição.

Dizem que por estar completa

Foi instalada a assembleia;

Mas que por não haver numero

Anda fazendo epiqueia!

Adeus, meu Jonio, desfruta

Bela paz, doce alegria,

E nunca sejas ingrato

À tua Rita Maria.

Esta versatilidade da carta deu-lhe outros usos, entre eles o da escrita do romance, cujo apogeu foi o século XVIII. Suas origens podem ser identificadas ao romance de Montesquieu, publicado em 1721, as Cartas Persas (2005), cujo modo de escrita - anônima, feita a partir de manuscritos encontrados - irá modular não apenas a escrita do romance epistolar, mas também a escrita das cartas publicadas em jornais e periódicos. Como afirma o autor, em escrito de 1754, o sucesso do livro deve-se ao fato de os leitores encontrarem nele "uma espécie de romance. Tem começo, 
andamento e fim. Os vários personagens são encadeados numa história que os liga". Montesquieu ainda observa que o sucesso do romance advém da sua capacidade de cada personagem expor "em pessoa sua situação atual - o que nos leva a sentir as paixões melhor do que qualquer narrativa poderia fazer" (2005, p. 239). Contudo, ressalta o autor, o grande mérito do seu escrito deve-se ao gênero escolhido, pois

escrevendo na forma de cartas, caso em que os atores não são selecionados e em que os assuntos tratados não dependem de nenhum propósito ou plano previamente elaborado, o escritor goza da vantagem de poder acrescentar a filosofia, a política e a moral a um romance, e de articular o conjunto inteiro por meio de uma cadeia secreta e, por assim dizer, desconhecida (Ibidem, p. 239, grifos do autor).

Neste tempo, a carta ganha um predicado não previsto por Cícero, Sêneca e outros autores célebres: a carta se transforma em ficção. De acordo com Christopher Conway, depois das Cartas Persas (1721), de Clarissa (1742), de Richardson, e de As ligações perigosas (1782), o "gênero epistolar se converte em um pretexto para jogar com a distinção entre ficção e verdade" (2006, p. 86). Podemos acrescentar a esta nova concepção aquela que prescinde do nome do autor, uma vez que o escrito apócrifo ganhou, desde as Cartas Persas, credibilidade, pois, como afirma o personagem Penny Júnior, personagem da comédia de Ben Jonson, The staple of news (1626) [O comércio de notícias], "para alguns, é a publicação impressa que é a novidade das notícias; eles têm como princípio não acreditar senão no que vêem impresso" (Apud, CHARTIER, 2007, p. 140). Nesta perspectiva, esta crença na palavra impressa perdurou por longo tempo e, por isso, pode-se compreender as palavras de José de Alencar, no epílogo da "Última Carta", dirigida ao Imperador, para justificar o anonimato: "Foi a consciência que me aconselhou o mistério. Para falar-vos com a franqueza precisa, era necessário ter um nome respeitado, cheio de prestígio e autoridade. Faltando-me esse título, só me restava o da verdade. A ideia é essencialmente democrática; ela nivela o trono com o povo. Fiz-me ideia, portanto, para ter o direito de interrogar a majestade" (ALENCAR, 2008, p. 150, grifos do autor).

Retomando as palavras de José de Alencar, observa-se uma representação tão significativa quanto a do personagem de Ben Jonson sobre o poder da palavra impressa, neste caso, sobre a palavra impressa em jornal, principalmente a palavra expressa através de cartas. Esta, contudo, não é a pri- 
meira vez que o autor demonstra o poder da palavra impressa em jornais e de como a escrita em jornais não prescindia de um nome de autor para ter efeito e ser lida. Em 1856, quando publicou suas Cartas sobre a Confederação dos Tamoios, no prólogo, que denominou de "Uma palavra", o autor informa: "Occultei a princípio o meu nome, não pelo receio de tomar responsabilidade do escripto; e sim porque obscuro como é, não daria o menor valor as ideas que emitti" (Idem, grifos do autor). Ao mesmo tempo em que exerce a captation benevolentiae, ${ }^{22}$ uma das regras da eloquência também aplicada à escrita epistolar, o autor demonstra, como defende D. F. McKenzie (2004), que a materialidade do texto influencia no processo de sua escrita e de sua leitura, pois do mesmo modo que as formas fazem com que os textos sejam lidos também participam da construção de seu significado. José de Alencar sabia disto ao fazer a seguinte observação:

Desde porém que critica, das columnas de um jornal passa ás folhas de um livro, entendo que é dever de lealdade para com o poeta que censurei, e para com o publico que me sérvio de juiz, assignar aquillo que escrevi. O leitor que julgou a Idea pelo que valia, sem o apparato de um nome conhecido, mas excitado pela curiosidade do mistério, dar-lhe-há de certo menos apreço quando souber quem a escreveu (1856, p. 9).

Alencar demonstra o modo próprio de escrever e de ler nos periódicos da época, que é diferente daquele do livro, em que a palavra, ou a ideia, vale mais do que o nome do autor, mas segundo uma perspectiva retórica. Segundo esta, mesmo em se tratando de um "conteúdo" a ser "transmitido", "a eficácia de persuasão necessariamente varia segundo o ajuste de aplicação de tais meios às diferentes circunstâncias de pessoa, tempo, modo e lugar relevantes em cada caso"(PÉCORA, 2001, p. 12).

Outro ponto a ser considerado diz respeito à "instabilidade dos gêneros" e a pressuposição de que o epistolar, como outros gêneros da época, "não é puro e inalterável em suas disposições, assim como o objeto não é idêntico à aplicação de um conjunto de prescrições encontradas em determinada preceptiva do período" (PÉCORA, 2001, p. 12). Em linhas gerais, conforme já

${ }^{22}$ Como parte do exórdio, a captation benevolentiae realiza a introdução ao relato dos fatos e tem a função de tornar o destinatário receptivo, favoravelmente disposto e atento; a simpatia do leitor pode ser obtida mediante referência do escritor a si mesmo, ao seu oponente, ao próprio leitor ou à ocasião (LAUSBERG, 1967). 
vimos anteriormente, pode-se aplicar aos periódicos do século XIX brasileiro o conceito de dissimulação honesta como "uma sinceridade verossímil", uma ficção da qual resulta uma escrita baseada em um composto de clareza e obscuridade, que pode ser evidenciado em qualquer escrito e não apenas na epistolografia. É evidente que ao leitor do periódico cabia o papel e a capacidade de garantir sentido ao que estava dissimulado, o que tornava a linguagem figurada um modo historicamente constituído de escrever e de ler de uma época, no suporte jornal. A seguir tem-se o exemplo de duas cartas publicadas em O Carapuceiro, de 10 de janeiro de 1842, que ilustra com bastante propriedade o comprometimento da linguagem dos periódicos com o presente e com a sua comunidade de leitores.

Copia fiel de duas cartas; isto he; huma d'hum labrego em Portugal a seu filho no Brasil, e outra deste em resposta a seu pai.

Mei filho Antonio - A benção de Deos te cubra, e mais a minha, que he bom-ha, junto com a de tua mãi, que está no Ceo para sempre de todos os seculos, e a de San Francisco recebendo as chagas, que não me deixará mentir; porque trez bezes com esta já te escrebi, e não me tens respondido. Manda-me dizer, se és morto para não te escreber mais; e se hes bibo, como nosso Senhor ha de prometir, manda me hum barril de melasso, e obra d'humas binte caixas de assucar; porque disse-me o compadre Zé Antunes, quando de la beio, que tu ja estabas tão adiantado, que ja eras terceiro em San Francisco, e com promessa de seres logo procuradori. Tua irmã e Joanna, mulher do Sacristão, pario a salbamento hum menino grande, como hum macho, Deos loubado, e ha de-se chamar Gonçalino, ou Gonçalito, que ha de ser hum regalo. Responde me, filho, para te encomendar a ialma ao Criadori dos ceos, e da terra, \&c. \&c.

Resposta.

Meu rico pai - Lebem me seiscentos diabos, se eu arrecebi as cartas, em que falla; e se eu fosse morto teria animo de negallo a Vm., que he mei pai, assim como eu sou se filho? Isto por cá não corre, como dantes; e por isso sò lhe posso mandar hum barrilinho do tal melasso. No mais fico ás suas ordens. \&c.

${ }^{23}$ Edmir Míssio (2004), ao discutir o conceito de dissimulação honesta em Accetto, faz uma arqueologia do termo e seu uso por vários redatores, desde Aristóteles a Baltazar Grácian. 
No contexto da produção da escrita/leitura epistolar daquele século, esta carta atualiza alguns lugares-comuns da ficção, compreendida como fantasia poética, ou como sinônimo de fingimento (MORAES, 1856), que pode empregar personagens ou uma narrativa para "ensinar" ou tratar de algum tema relevante. A leitura "verossímil" deste escrito exigiria o conhecimento de uma série de circunstâncias que teriam favorecido a sua escrita. $\mathrm{O}$ seu caráter jocoso é visível, principalmente pela insistência com que os autores $\mathrm{da}$ carta - tanto pai quanto filho - insistem em trocar a letra $\mathrm{b}$, pela letra $\mathrm{v}$ -, cujo uso pode levantar algumas possibilidades que vão desde a escrita errada do ponto de vista da ortografia e de sua fixação até a defesa da tese de algum linguista sobre o que se chamava "pronunciação", ou o uso de estrangeirismos, matérias de interesse de alguns jornais e periódicos.

Com efeito, a epístola nos jornais brasileiros do século XIX é resultante de uma "tendência histórica básica dos mais diferentes gêneros", qual seja "desenvolver formas "mistas", com "dinamicidade relativa nos distintos períodos, que impedem definitivamente a descrição de qualquer objeto como simples coleção de aplicações genéricas" (PÉCORA, 2001, p. 12). Neste caso, as cartas nos jornais têm como origem a carta apologética, objeto literário no qual a epístola é utilizada para o combate e a defesa de ideias, cuja presença é anterior à imprensa brasileira ou portuguesa, atestada desde o século XVII, pela "Carta Apologética", do Padre Antonio Vieira, "escrita em castelhano e dirigida ao padre Jácome Iquazafigo, Provincial da Andaluzia, em 30 de abril de 1686"24 (HANSEN, 2003, p. 10). Francisco José Freire, ao diferenciar a carta apologética daquela de defensoria, define a primeira como carta que, "de ordinario discorrem sobre materias, em que se censuraõ os ditos, ou escritos de alguém". Ao contrário das cartas de defensoria, escritas para amigos, "as apologeticas são Cartas públicas contra pessoas maldizentes, de sorte que as resposta a ella devem ser fortes, e encaminharem-se ao público". Por fim, a "apologia atende pela maior parte a responder às censuras feitas sobre diversas cousas”(1823, p. 272-273). Freire ainda determina como se dá a trama ou a contextura deste tipo de carta:

\footnotetext{
${ }^{24}$ Segundo Hansen (2003, p. 10 ), trata-se da defesa de uma “interpretação profética das Trovas, Bandarra, contra o texto Respuesta a uma Carta, que Antonio de Vieira Monopanto escrivió a um Señor Obispo de la Orden de los Predicadores, de autoria de um anônimo oculto sob o pseudônimo Escoto Patavino. A Carta Apologética foi publicada em 1757 e a Mesa Censória a proibiu como falsa, sediciosa, temerária e infame, fazendo-a queimar por um carrasco, em 1768".
} 
Poucos são os que neste assumpto saciaõ a sua sede com água pura, porque commumente lemos que os censores ${ }^{25}$ escrevem libellos famosos, os censurados vomitaõ venenos, que manchaõ a parte mais delicada, qual he a honra. Finalmente a apologia deve principar por huma pequena contra o censor, fingindo que senaõ sabe que cousa o moveo a pegar na penna: e esta parte deve ser moral, mostrando que nos compadecemos delle (1823, p. 273).

Seja na imprensa brasileira, seja na imprensa venezuelana ou portuguesa, "a carta se converteu em elemento-chave de sociabilidade e a sua publicação (confiáveis ou apócrifas) funcionava para construir reciprocamente uma comunidade de leitores"(CONWAY, 2006, p. 86). Se nos primeiros jornais nacionais, a exemplo do Gazeta do Rio de Janeiro, observamos sua presença de forma tímida e restrita a "autores", cujos títulos e nomes estavam relacionados à nobreza e às classes políticas dominantes, ao longo do século, contudo, esta prática de escrita se popularizou e passou até mesmo a compor a estrutura do jornal, dando origem à seção Correspondência. Tomemos como exemplo, o Correio Braziliense, ou o Armazém Literário, o primeiro jornal brasileiro a ser editado em Londres. Vemos, lado a lado, a presença dos documentos oficiais e das cartas particulares ou familiares, algumas apócrifas, que utilizavam as páginas do jornal para emitir opinião, desacreditar o discurso oficial, com função didática e educativa. Mesmo sendo verificada a presença de epístolas em praticamente todos os exemplares do Correio Braziliense, apenas em novembro de 1808 é criada a seção Correspondência do jornal de Hipólito José da Costa, prática que seria tomada como modelo para basicamente todos os jornais brasileiros.

Afinal, o que teria favorecido a presença tão determinante da epístola nos periódicos? O que teria determinado este casamento tão harmonioso entre o suporte jornal e o gênero epistolar, a ponto de um se tornar quase sinônimo do outro? Em primeiro lugar, tem-se a hipótese de Rizzini, segundo a qual "verifica-se terem sido os correios, e não a tipografia, a determinante do periodismo" (1988, p. 42). É que a organização e a circulação semanal imposta pelos correios gerou uma regularidade semelhante àquela verificada com as gazetas. Segundo Hunt,

${ }^{25}$ Censor aqui deve ser compreendido no contexto do século XVIII, palavra que segundo o Diccionario da lingua portugueza, de Antonio de Moraes Silva, significa §fig. O que critica, censura obras literárias. 
a palavra gazeta tem como origem a leitura dos editais públicos, escritos à mão, durante o período em que os Turcos estavam em guerra contra os venezianos; essas descrições dos acontecimentos importantes eram lidos publicamente em Veneza para um público em que cada um pagava uma moeda chamada gazetta, para ter o privilégio de ouvi-las. Desde então, a origem da palavra Gazeta é aplicada aos papéis que contêm notícias (1850, p. 36). ${ }^{26}$

No Novo Diccionario da lingua portuguesa (1843), por José da Fonseca, a palavra gazeta consta como sinônimo de Mercúrio, que tem por definição "azzogue; corretor de correspondencias amorosas". A carta passa a se constituir, ainda segundo Rizzini , como "uma crônica da semana", "pelo que foi a primeira forma de jornalismo a beneficiar-se da tipografia" (1988). Esta mesma perspectiva é adotada por Conway, ao tratar da carta no periódico Gazeta de Caracas. Segundo o autor, esta íntima relação deve-se ao fato de ambos, correio e periódico, chegarem no mesmo navio "para um público ávido por notícias do mundo” (2006, p. 86). A relação indissociável que se estabeleceu entre a correspondência e o jornal pode ser entrevista, entre outras, pela forma como a palavra foi registrada em dicionários da época. $\mathrm{Na}$ edição de 1813, do Dicionário da língua portuguesa, de Antonio de Moraes, no verbete correspondência e correspondente não existe qualquer alusão ao suporte jornal. Para o dicionarista, o primeiro significa "O acto de responder ao que tem negocio comnosco, ao que nos escreve $\$$. Escritos em resposta: v.g. foi-lhe apreendida toda a correspondencia, que tivera c'os inimigos"; a correspondente, designa "o que trata negocios de outro socio, ou amigo em letra diversa".

Contudo, a origem da correspondência e dos correspondentes, ou a ideia da carta como suporte de notícias em jornais, pode estar em uma época mais anterior, ligada à origem da imprensa inglesa. Nathanaiel Butter foi o primeiro da sua época, em 1622, a imprimir o que vinha sendo escrito a mão durante muito tempo; pioneiro em dar aos panfletos informativos uma feição que distinguirá o jornal da gazeta e o transformará no impresso que conhecemos como jornais e periódicos. Desde então, as

\footnotetext{
${ }^{26}$ Somewhat similar public notices of public events were written during the period when the Turks were waging war with the Venetians; and its stated that, in 1563, these descriptions of important occurrences were publicly these descriptions of important occurrences were publicly read in Venice to audiences who each paid a coin called gazetta for the privilege of listening. Hence the origin of the word Gazette as applied to papers containing News.
} 
gazetas passaram a ser publicadas periodicamente, com uma semana de intervalo entre uma e outra (HUNT, 1850, p. 11). Nathaniel Butter pertence às origens de um projeto pioneiro de jornal. Ele havia sido um newswriter; um autor de newsletter: que consistia em um tipo profissional que, sediado em Londres como correspondente geral, despachava pacotes de notícias para pessoas de todo o país com dinheiro suficiente para gastar com tal luxo (Ibidem). Chartier (2007), em análise sobre a ambiguidade da notícia impressa revelada nas peças de Ben Jonson, dramaturgo inglês que primeiro levou para os palcos o comércio de notícias, Staples of News [Comércio de Notícias](1626), chama a atenção para o fato de que, antes desta, o autor encenou uma "máscara", ${ }^{27}$ Newes from the New World [Notícias do Novo Mundo] (1620), em que descreve, pela fala do personagem Factor, o processo do comércio de notícias e mostra como a carta era o gênero pelo qual circulavam-nas: "Escrevo, normalmente, minhas mil cartas por semana e, às vezes, mil e duzentas; assim mantenho meu comércio e, ao mesmo tempo, minha reputação junto aos meus próprios agentes na cidade e a meus correspondentes nas províncias" (JONSON apud CHARTIER, 2007, p. 158). Outro exemplo, agora da França, que ilustra esta relação íntima da carta com o comércio de notícia é dada por Chartier, a partir de uma carta de 1674, escrita por um dos secretários empregados na oficina de Sir Joseph Williamson, na qual afirma que

para dar conta de uma centena de correspondentes, cada escriba deve copiar, na terça, dezesseis cartas (quatro longas que deem as notícias de uma semana e doze curtas que contenham as notícias de dois dias apenas); na quinta, treze cartas, três longas e dez curtas e, no sábado, sete longas, quatro com as notícias de quatro dias e oito curtas. Cada copista devia, assim, produzir 24 folhas de escrita jornalística por semana (CHARTIER, 2007, p. 159).

Este comércio de notícias, satirizado por Ben Jonson, se pautava pelo critério de estas serem autênticas ou apócrifas, a depender do profissional que a vendia. E não eram apenas as manuscritas: “[...] são suspeitas as notícias que circulam nas gazetas impressas, Coranti and Gazetti, recém lançadas" (CHARTIER, 2007, p. 134). Estas cartas tiveram tão grande importância que, mesmo após a imprensa, elas não foram esquecidas, como demonstra Hunt,

${ }^{27}$ Segundo Chartier (2007, p. 130), “máscara”, de acordo com o léxico inglês, é um balé da corte. 
com o jornal publicado por Ichabod Dawks, em 1696, “as quais eram impressas em caracteres e em papel de cartas para imitar uma escrita comum, onde um fragmento era deixado em branco para ser preenchido pelo comprador antes de ser despachado pelo correio"28 (1850, p. 166).

De fato, esta prática da correspondência originada das antigas newsletters inglesas permanece como modelo para a imprensa brasileira do século XIX. Observe-se no exemplo anteriormente citado, o no 103 do Idade d'Ouro no Brasil, de 26 de dezembro de 1815, o uso corrente à época para a palavra correspondência, quando a gazeta anuncia que "O seu Proprietario abrio huma correspondencia para Londres, e Paris a fim de ter sempre os melhores Periodicos da Europa para a redacção da Gazeta”. Ao longo do século, contudo, a palavra mantém nos dicionários a sua original designação, sem qualquer referência aos jornais. Contudo, já no fim do século XIX, as palavras correspondência e correspondente revelam, no Novo dicionário de língua portuguesa (1899), de Candido de Figueredo, a sua relação com os jornais, pois, entre os vários sentidos, inclui-se o de correspondência significando "a carta a um periódico" e o termo correspondente passa a designar "aquele que escreve correspondências em periódicos".

\section{Considerações finais}

Esta pesquisa ainda não está concluída, mas alguns resultados já podem ser levantados. O primeiro deles corrobora com a hipótese levantada por Carvalho (2010), segundo a qual a retórica deve ser a chave de interpretação para a leitura da história intelectual do Brasil. Contudo, sua "insistente presença” e a longuíssima duração derivam menos do seu ensino ou do seu conhecimento através de manuais populares, haja vista a instabilidade própria dos gêneros retóricos que não são puros ou imutáveis em suas “disposições, assim como o objeto não é idêntico à aplicação de um conjunto de prescrições encontradas em determinada preceptiva do período, uma vez que paráfrases de manuais de retórica não dão conta dos sentidos específicos dos objetos"(PÉCORA, 2001, p. 12).

No caso da epístola, o gênero contemplado por este trabalho, pode-se afirmar que sua presença nos jornais brasileiros do século XIX é resultante

\footnotetext{
${ }^{28}$ Hunt (1850, p. 166) [which was printed in script, and on letter-paper to imitate an ordinary handwriting, a portion being left blank to be filled up by the purchaser before he dispatched it by post].
} 
de uma "tendência histórica básica dos mais diferentes gêneros", qual seja, "desenvolver formas "mistas", com "dinamicidade relativa nos distintos períodos, que impedem definitivamente a descrição de qualquer objeto como simples coleção de aplicações genéricas" (Ibidem). Junte-se a esta dinamicidade a própria versatilidade do gênero epistolar que, escrito em prosa ou em verso, servia aos mais diferentes propósitos, ou a quase todos, como sugere Freire de Carvalho, não havendo assunto de que não pudesse tratar. Por isto, os manuais, entre eles o de Candido Lusitano, já previam as cartas mistas.

Outro dado a considerar, tal qual previsto pelos escritores daquele tempo, é a inclusão da carta no campo dos objetos "literários", do qual faziam parte todos os objetos da retórica e da poética e as composições escritas e apropriadas como literatura, cujo conceito estético, que privilegiava alguns gêneros, foi anacronicamente aplicado a todos os objetos do século XIX.

Por fim, é necessário considerar a presença marcante da leitura de jornais e de periódicos como forma de educação e de formação das práticas de escrita, bem como o fato de o gênero epistolar ser predominante na escrita de opinião, nos embates, nas contendas literárias, o que, ao mesmo tempo em que ensina como escrever, também informa os modos de ler. Também inscrita em uma tradição, mas anterior à instauração até mesmo da imprensa lusa, como comprova as cartas do Padre Antonio Vieira, observa-se que a carta apologética passou a ser o modo recorrente de escrever cartas em periódicos, revelando a "dinamicidade dos gêneros" como tendência histórica de todo objeto escrito.

\section{Referências Bibliográficas}

ABREU, Márcia. Letras, Belas-letras, Boas Letras. In: BOLOGNINI, Carmem Zink (Org.) História da literatura: o discurso fundador. Campinas: Mercado de Letras, ALB, Fapesp, 2003. (Coleção Histórias de Leitura).

ALENCAR, José de. Cartas a favor da escravidão. Org. PARRON, Tânia. São Paulo: Hedra, 2008.

. Cartas sobre a Confederação dos Tamoios.

AMED, Fernando. As cartas de Capistrano de Abreu: sociabilidade e vida literária na belle époque carioca. São Paulo: Alameda, 2006.

ARAÚJO, Jorge de Souza. Perfil do leitor colonial. Salvador: UFBA; Ilhéus: UESC, 1999. 
BAKHTIN, Mikhail. Marxismo e filosofia da linguagem. São Paulo: Hucitec, 2004.

BARBOSA, S. de Fátima P. Literatura e periódicos no século XIX: perspectivas históricas e teóricas. Porto Alegre: Nova Prova, 2007.

A espada das palavras: a escrita epistolar nos periódicos portugueses e brasileiros do século XIX. Atas do $5^{\circ}$ Colóquio do PPRLB. Real Gabinete Português de Leitura: Rio de Janeiro, 2010. Disponível em: <http:// rgplgead.bibliopolis.info/GeADOPAC/\#/SearchAdv>. Acesso em: $22 \mathrm{dez}$. 2010.

BASTOS, M. H. Câmara et al. (Org.). Destinos das letras. História, educação e escrita epistolar. Passo Fundo: UPF, 2002.

CARVALHO, F. Freire de. Lições elementares de eloquência nacional para uso da mocidade de ambos os hemispherios, que falla o idioma portuguez. 5. ed. Lisboa: Typographia Rollandiana, 1856.

CARVALHO, J. Murilo. História intelectual no Brasil: a retórica como chave de leitura. Topoi, Rio de Janeiro, n. 1, p. 123-152. Disponível em: <http:// www.ifcs.ufrj.br/ ppghis/pdf/topoila3.pdf>. Acesso em: 12 dez. 2010.

CERTEAU, Michel de. A escrita da história. 2. ed. Rio de Janeiro: Forense Universitária, 2006.

CHARTIER, Roger. Inscrever e apagar. São Paulo: Editora da Unesp, 2007. CONWAY, Christopher. Letras combatientes: gênero epistolar y modernidade en la Gaceta de Caracas, 1808 -1822. Revista Iberoamericana. v. LXXII, n. 214, p. 77-91, enero/marzo. 2006.

Darnton, Robert. O grande massacre dos gatos. Rio de Janeiro: Graal, 1986. GALVÃO, Walnice; GOTLIB, Nádia. Prezado senhor, prezada senhora: um estudo sobre cartas. São Paulo: Companhia das Letras, 2000.

GAMA, M. do S. Lopes. Lições de eloquência nacional. Editora de Paula Brito, 1846 .

GOMES, A. de Castro (Org.). Escrita de si, escrita da história. Rio de Janeiro: FGV, 2004. 
GOMEZ, Antonio Castilho. Como polvo e o camaleão se transformam: modelos e práticas epistolares na Espanha moderna. In: BASTOS, M. H. Câmara et al. (Org.). Destinos das letras. História, educação e escrita epistolar. Passo Fundo: UPF, 2002.

HANSEN, J. Adolfo (Org.) Introdução. In: VIEIRA, Antonio. Cartas do Brasil. 1626 -1697. São Paulo: Hesdra, 2003.

HUNT, F. Knight. The fourth estate: contributions towards a history of newspapers, and the liberty of the press. London: David Bogue, 1850. Disponível em: <http://books.google.com.br/>.

LAUSBERG, Heinrich. Elementos de retórica literária. 2 ed. Lisboa: Fundação Calouste Gulbenkian, 1967.

LIMA SOBRINHO, Barbosa. Os precursores do conto no Brasil. Rio de Janeiro: Civilização Brasileira, 1960. (Panorama do Conto Brasileiro 1).

LUSTOSA, Isabel. O nascimento da imprensa brasileira. Rio de Janeiro: Jorge Zahar Editor, 2003.

MCKENZIE, D. F. Bibliography and the sociology of texts. In: Bibliography and the sociology of texts. Cambridge: Cambridge University Press, 2004.

MASSUD, Moisés. Dicionário de termos literários. São Paulo: Cultrix, 1985. MEYER, Marlyse. Folhetim: uma história. São Paulo: Companhia das Letras, 1996.

MÍSSIO, Edmir. Acerca do conceito de dissimulação honesta de Torquato Accetto. Tese (Doutorado) - Unicamp, Campinas, 2004.

MONTESQUIEU, Charles de. Cartas Persas. Trad. Renato Janine Ribeiro. São Paulo: Nova Alexandria, 2005.

MORAES, A. J. Mello. Elementos de litteratura. Contendo a arte poetica, a mythologia, a idiologia, a grammatica, a logica e a rhetorica extraídas, para uso dos seus filhos. Rio de Janeiro: Typographia Americana de José Soares de Pinho, 1856. Disponível em: <http://books.google.com.br/ books?hl=pt-br>.

PÉCORA, Alcir. Máquina de gênero. São Paulo: Edusp, 2001. 
USP. Revista Teresa. Revista do Departamento de Letras Clássicas e Vernáculas da Faculdade de Filosofia, Letras e Ciências Humanas da USP, n. 8/9. São Paulo: Editora 34, 2008.

RIZZINI, Carlos. O livro, o jornal e a tipografia no Brasil. São Paulo: Imprensa Oficial, 1988.

ROQUETE, J. I. Novo secretário português ou código epistolar. 3. ed. Paris: Aillaud, 1860.

SCHOPENHAUER, Arthur. A arte de escrever. Porto Alegre: L\&PM, 2006. SILVA, O. Machado da. Retórica, roda de compadres, solidão e achaques da velhice: o Machado de Assis das cartas. Dissertação (Mestrado) - UFPB, João Pessoa 2009.

SOUSA, R. Acízelo. O império da eloquência. Rio de Janeiro: Eduerj; Niterói: Eduff, 1999.

VERNEY, Luís António. Verdadeiro Método de Estudar. Lisboa: Editorial Presença, 1991.

VIANNA, Hélio. Contribuição à história da imprensa brasileira: 1812-1869. Rio de Janeiro: Imprensa Nacional, 1945. 